\title{
Anesthetic Management of a Parturient with Poliomyelitis Associated with Kyphoscoliosis
}

\author{
Shrestha AB, Shrestha S, Sharma KR, Gurung T \\ Department of Anesthesiology, Paropakar Maternity and Women's Hospital, Thapathali, Kathmandu, Nepal.
}

A 27-year-old primigravida with poliomyelitis associated with kyphoscoliosis underwent cesarean section under spinal anesthesia. Anesthesia poses a significant risk to a parturient with kyphoscoliosis and there is no single regimen that can be recommended for anesthetic management. Regional anesthesia is also challenging for anesthesiologist because the distortion of the spinous process and rotation of the vertebral column. The perioperative period was uneventful. Spinal anesthesia can be safely administered with less adverse effects in poliomyelitis patients with kyphoscoliosis.

Keywords: cesarean section, kyphoscoliosis, poliomyelitis, spinal anesthesia.

\section{INTRODUCTION}

Poliomyelitis is a neuromuscular disorder caused by poliovirus (enterovirus). This disease was eradicated from most parts of the world with the success of vaccination programs, but it is still a problem in some tropical countries. Polio cases have decreased by over $99 \%$ since 1988 , from an estimated 350000 cases then, to 406 reported cases in 2013. ${ }^{1}$ Polio virus is transmitted through faecal-oral route. It selectively damages motor and autonomic nervous systems. Most commonly affected areas are neurons in anterior horns of the spinal cord, vital centers in the medulla, cranial nerve nuclei and nuclei in the roof of the cerebellum. Patients with polio may suffer from sequelae of the acute illness and may develop chronic neurological and respiratory complications related to the long-term effects of their disease. Poliomyelitis is associated with scoliosis in $30 \%{ }^{2}$ patients when compared to its prevalence in general population which is $0.3-15.3 \% .^{3-5}$

Poliomyelitis is more common in adolescents and has female to male ratio of $3: 1$. Central neuraxial block is controversial in these patients and poses an anesthetic challenge, in view of identifying the intervertebral space, performing lumbar puncture, difficulty in predicting the extent of block..$^{6-8}$

\section{CORRESPONDENCE}

Dr Amir Babu Shrestha

Department of Anesthesiology

Paropakar Maternity and Women's Hospital

Thapathali, Kathmandu, Nepal.

Email: ameer122@hotmail.com

Phone: +977-9851066934.
Anesthetic concerns for providing general anesthesia to patients with poliomyelitis and kyphoscoliosis are increased sensitivity to sedative drugs, prolonged effect of non-depolarizing neuromuscular blocking agents, dysfunctional autonomic nervous system, underdeveloped muscles of respiration making extubation difficult. ${ }^{9}$

Here we report an anesthetic management of a pregnant woman presenting for elective cesarean delivery who had poliomyelitis and kyphoscoliosis.

\section{CASE}

A 27 years old primigravida at 37 weeks of gestation, weighing $50 \mathrm{~kg}$ and $145 \mathrm{~cm}$ in height presented to the emergency department of our hospital with the chief complaint of decreased fetal movement for two days. On evaluation, she was not in labor, however she was suffering from poliomyelitis since childhood and developed kyphoscoliosis four years back. Prior to pregnancy, she had reasonable exercise tolerance as evidenced by her ability to walk with support and absence of any shortness of breath. Her exercise tolerance had decreased as pregnancy progressed. She denied any symptoms of orthopnea and paroxysmal dyspnea and had no any symptoms of cardiovascular instability.

General examination she was unremarkable with pulse rate of 117 beats per min, blood pressure of $120 / 70 \mathrm{mmHg}$ and $\mathrm{SPO}_{2}$ of $94 \%$ in room air. Neurologically, her motor power of both lower limbs was $4 / 5$ with no sensory deficit. She had severely deformed spine causing difficulty in palpation of intervertebral space (Figure 1). The anteroposterior diameter of her chest wall was increased secondary 
to the overcrowding of the ribs (Figure 2). Chest auscultation revealed bilateral normal vesicular breath sounds with no added sound. Airway examination revealed a Mallampati grade 2 and free neck mobility. Other systemic examination revealed no significant abnormalities. Her investigation reports were within normal value. Despite of the neurological deficit and anatomical difficulty, we planned for a cesarean section under regional anesthesia; spinal anesthesia.

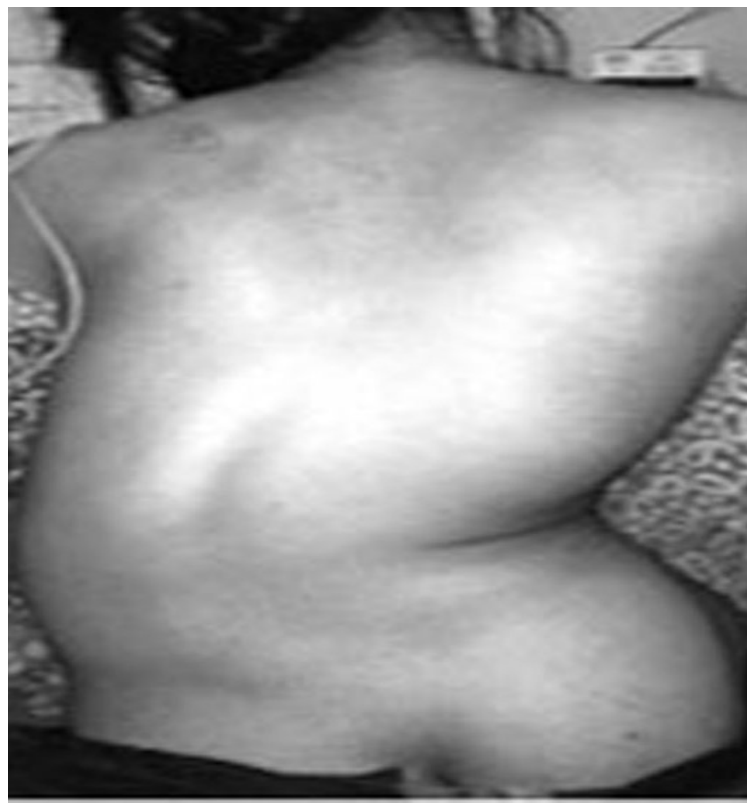

Figure 1. Back showing the deformity of spine.

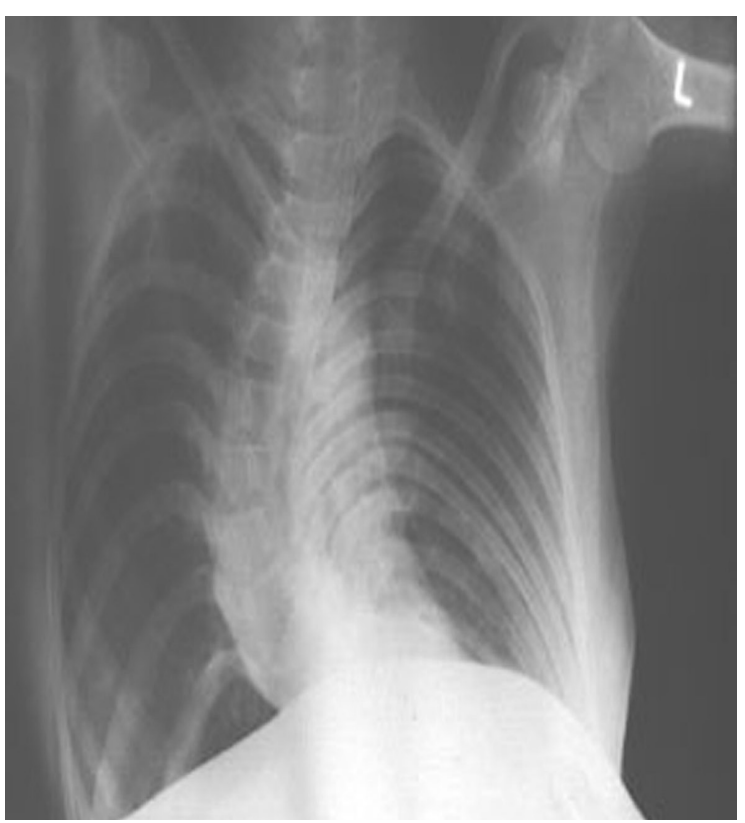

Figure 2. Chest X-ray PA view.
On the day of surgery, intravenous line was opened with a wide bore 16 gauge cannula in dorsum of the left hand and premedicated with Metoclopromide $10 \mathrm{mg}$ and Ranitidine $50 \mathrm{mg}$. Preloading was done with $500 \mathrm{ml}$ Ringer lactate solution according to our hospital protocol for the cesarean section. Monitor was attached for measurement of baseline heart rate, non invasive blood pressure, $\mathrm{SpO} 2$ and ECG. She was kept in sitting position. Despite unclear landmarks and anatomical difficulty in localizing the intervertebral space puncture was successfully made in the second attempt at the level of L4 -L5 via 26G Quincke spinal needle. Spinal anesthesia was achieved by administrating total $2 \mathrm{ml}$ of drug containing $1.5 \mathrm{ml}$ of $0.5 \%$ heavy Bupivacaine and 0.5 $\mathrm{ml}$ of $25 \mu \mathrm{g}$ Fentanyl. The sensory block was achieved up to T6 level after 15 minutes. Intraoperative period was uneventful with the outcome of alive female baby weighing $2.5 \mathrm{~kg}$. The motor block regressed 3 hours after administration of spinal anesthesia and sensory block regressed by 4 hours. Both mother and baby were healthy.

\section{COMMENT}

Kyphoscoliosis is a disorder characterized by progressive deformity of spine consisting of lateral and posterior curvatures. In majority, it is of idiopathic etiology, which account for $80 \%$ of case. ${ }^{10}$ Secondary kyphoscoliosis occurs as a result of various neuromuscular, vertebral or connective tissue disorders. ${ }^{11}$ In our case it was due to poliomyelitis. The level of derangements in cardiac and pulmonary function of kyphoscoliosis patient is related to the amount of Cobb's angle in thoraco-lumbar X-ray. If this angle is larger than 40 degrees the cardiopulmonary function frequently decreases, and if larger than 100 degrees, it significantly decreases. ${ }^{12,13}$ In our patient we didn't find any signs and symptoms of cardiopulmonary disease. Due to the lack of the facilities, pulmonary function test and arterial blood gas analysis were not performed; otherwise the test results would be of immense help in making decisions regarding the mode and time of delivery and requirement of ventilatory support.

In kyphoscoliosis, there is impaired growth of the lungs, early in their development, due to the thoracic deformity causing a decrease in the lung volume, alveolar hypoventilation, reduced diffusion 
capacity and chest wall compliance, and increased pulmonary vascular resistance and pulmonary arterial hypertension..$^{14}$ Pulmonary arterial hypertension is due to increased resistance to blood flow in small pulmonary vessels, intrinsic pulmonary parenchymal disorder, chronic hypoxemia, and reduction in the pulmonary vascular bed by the thoracic deformity. Thus, anesthesia poses a significant risk to a parturient with kyphoscoliosis and there is no single regimen that can be recommended for anesthetic management. Neuraxial anesthesia is currently the technique of choice for operative deliveries as the risk of maternal mortality during general anesthesia is higher. ${ }^{15,16}$ General anesthesia may be required in kyphoscoliosis patient because of maternal preference, cardiopulmonary disease or difficulty in performing regional anesthesia. General anesthesia is more challenging for anesthesiologist because respiratory depressant effect of the general anesthetic drugs causes alveolar hypoventilation leading to acidosis, hypercarbia, and hypoxia and eventually may lead to increase in pulmonary arterial pressure leading to right heart failure. Positive pressure ventilation reduces venous return and the negative inotropic effect of the anesthetic agent can lead to severe reduction in blood pressure. Coughing and bucking at the end of surgery may transiently but significantly decrease functional residual capacity resulting in further ventilation-perfusion mismatch and hypoxemia. ${ }^{17}$ Severe scoliosis associated with altered anatomy of the airway causing difficulty in laryngoscopy and intubation. Care should be taken to avoid hypoxia, hypercapnea, acidosis, and anesthetic gases such as nitrous oxide as they increase the pulmonary vascular resistance. All these factors may lead to delay in extubation and need for postoperative ventilation.

Regional anesthesia in kyphoscoliosis is challenging because the distortion of the spinous process and rotation of the vertebral column. During pregnancy due to increased intra-abdominal pressure and engorged veins in the epidural the subarachnoid space is decreased. In such cases, the normal dose of the local anesthetic can lead to higher levels of block leading to hypotension. ${ }^{18}$ The dose of local anesthetic should be adjusted according to the height and weight of the patient to get desirable sensory and motor block without hypotension. But severe kyphoscoliosis is associated with further reduction in volume of cerebrospinal fluid in subarachnoid space requiring low dose of anesthetic drugs. Moran DH et $\mathrm{al}^{19}$ have reported that due to the curvature of the spine, the hyperbaric solutions of the anesthetic drugs tend to pool in the dependent portions of the spine leading to inadequate block. Addition of isobaric preparations of local anesthetic drug improves the quality of the block. Similarly in our case we administered $1.5 \mathrm{ml}$ of hyperbaric Bupivacaine and Fentanyl $0.5 \mathrm{ml}(25 \mu \mathrm{g})$ and the level of block was achieved in 15 minutes. The onset of subarachnoid block was prolonged in our patient compared to other parturients.

There are few reports of anesthetic management in kyphoscoliosis parturient using solely epidural, combined spinal epidural, ${ }^{20}$ continuous spinal anesthesia ${ }^{19}$ and general anethesia ${ }^{16}$ with successful outcomes. So, depending on the facilities available for the peripartum period, any anesthetic technique can be chosen as we did in our case.

\section{CONCLUSIONS}

In conclusion, there is no single preferred anesthesia that fits for all patients with kyphoscoliosis. Thus patient must be evaluated meticulously regarding skeletal abnormality as well as cardiovascular physiology. With the experience of our patient and the published literature spinal anesthesia appears to be the safest and most appropriate type of anesthesia in patients with kyphoscoliosis undergoing cesarean section.

\section{DISCLOSURE}

The authors report no conflicts of interest in this work.

No violation of human rights and safety.

Funding: Nil

\section{REFERENCES}

1 World Health Organization. Poliomyelitis. Updated on May 2014. Retrieved on May 2014. Available from URL: http:// www.who.int/mediacentre/factsheets/fs114/en/

2 Colona PC, Fredreick VS. A study of paralytic scoliosis based on five hundred cases of poliomyelitis. J Bone Joint Surg. 1941;23:335-53.

3 Koukourakis I, Giaourakis G, Kouvidis G, Kivernitakis E, Blazos J, Koukourakis M.Screening school children for scoliosis on the island of Crete. J Spinal Disord. 1997; 10:527-31. 
4 Stirling AJ, Howel D, Millner PA, Sadiq S, Sharples D, Dickson RA. Late- onset idiopathic scoliosis in children six to fourteen years old: A cross-sectional prevalence study. J Bone Joint Surg Am. 1996;78:1330-6.

5 Lonstein JE. Adolescent idiopathic scoliosis. Lancet. 1994;344:1407-12.

6 Hebl JR, Horlocker TT, Schroeder DR. Neuraxial anesthesia and analgesia in patients with preexisting central nervous system disorders. Anesth Analg. 2006;103:223-8.

7 Lambert DA, Giannouli E, Schmidt BJ. Postpolio syndrome and anesthesia. Anesthesiology. 2005;103:638-44.

8 Chin KJ, Chan VW, Ramlogan R, Perlas A. Real-time ultrasound-guided spinal anesthesia in patients with a challenging spinal anatomy: two case reports. Acta Anaesthesiol Scand. 2010;54:252-5.

9 Ballarapu GK, Aloka S, Veldurti AKK, Padmaja D, Gudaru J. Spinal anesthesia in poliomyelitis patients with scoliotic spine: A case control study. Indian J Anaesth. 2013; 57(2):145-149.

10 Dongare HC, Khatib KI, Baviskar AS. Principles of Anesthetic Management in patients with Congenital Kyphoscoliosis undergoing Laparotomy. Indian Journal of Applied Research.2013;3(9):444-46.

11 Kearon C, Viviani GR, Kirkley A, Killian KJ. Factors determining pulmonary function in adolescent idiopathic thoracic scoliosis. Am Respir Dis. 1993;148:288-94.

12 Stoelting RK, Dierdorf SF: Anesthesia and co-existing diseases. $3^{\text {rd }}$ ed. New York: Churchill-Livingstone; 1993. p. $452-53$.

13 Bergofsky EH, Turino GM, Fishman AP: Cardiorespiratory failure in kyphoscoliosis. Medicine 1959; 38: 263-317.

14 Naeye RL. Kyphoscoliosis and cor pulmonale; a study of the pulmonary vascular bed. Am J Pathol. 1961; 38:561-73.

15 American Society of Anesthesiologists Task Force on Obstetric Anesthesia. Practice guidelines for obstetric anaesthesia: An updated report by the American Society of Anesthesiologists Task Force on Obstetric Anaesthesia. Anesthesiology. 2007;106:843-63.

16 Hawkins JL, Chang J, Palmer SK, Callaghan WM, Gibbs CP. Anesthesia related maternal mortality in the United States $1997-2002$. Anesthesiology. 2008;109:206

17 Bickler PE, Dueck R, Prutow RJ. Effects of barbiturate anaesthesia on functional residual capacity and ribcage/ diaphragm contribution to ventilation. Anesthesiology. 1987;66:147-52.

18 Klienman W, Mikhail M-Spinal,Epidural, and Caudal Blocks.In :Morgan GE, Mikhail SM, Murray MJ. Clinical Anaesthesiology. $4^{\text {th }}$ ed. New York:Mc Graw Hill Inc; 2006:289-323.

19 Moran DH, Johnson MD. Continuous Spinal Anaesthesia with Combined Hyperbaric and Isobaric Bupivacaine in a Patient with Scoliosis. Anesth Analg. 1990;70:445-7.

20 Pan PH, Moore CH. Doxorubicin-induced Cardiomyopathy: Three Case Reports of Anesthetic Management for Caeserean and Vaginal Delivery in Two Kyphoscoliotic Patients. Anesthesiology. 2002;97:513-5 